\title{
A statistical approach to analyze user behaviour in road evacuation
}

\author{
F. Russo \& G. Chilà \\ Università degli Studi Mediterranea di Reggio Calabria, \\ DIMET - Dipartimento di Informatica, Matematica, \\ Elettronica e Trasporti, Italy
}

\begin{abstract}
The international literature related to evacuation conditions proposes many studies which focus on the hurricane emergency case and consider revealed preference (RP) surveys for demand model estimation. As RP data are not available for all dangerous events, such models, derived from observation of past evacuation behaviour, cannot be directly applied to other dangerous events. Prediction of user behaviour becomes essential. For this purpose, evacuation trials and stated preference (SP) surveys may be conducted. As a first step, statistical analysis of stated behaviour in emergency conditions could be carried out. In this work we propose several hypothetical scenarios, which could be classified as SP scenarios, considering three different dangerous situations, with delayed effects in time. A sample of users is considered and their responses are statistically analyzed to study user behaviour in evacuation conditions.
\end{abstract}

Keywords: evacuation conditions, hypothetical scenarios.

\section{Introduction}

In evacuation conditions, demand models specified and calibrated in ordinary conditions cannot be directly applied for several reasons [1,2]. The international literature related to evacuation conditions proposes many studies which focus on the hurricane emergency case and which consider demand model estimation revealed preference (RP) surveys. The latter supply preferences inferred from observations of a decision maker's actual choices, in relation to real contexts.

In much of the literature, two user decisions are simulated: whether or not to evacuate and when. These decisions are simulated through a statistical approach, 
using simple relationships such as means, rates and distributions [3]. For example, the most common method of estimating evacuation demand is to use evacuation participation rates in evacuation zones. These rates are a function of the severity of the storm and are based on past observed behaviour [3]. Response curves, sensitive to the characteristics of the hurricane, time of day, type (mandatory, advised,...) and timing of evacuation order, have also been used to simulate evacuation demand. Such curves have been subjectively established based on past evacuation behaviour and plot the proportion evacuating against the time from issuing an evacuation order [4].

A different way is to specify a model in which the analyst introduces a probabilistic approach and hypothesizes the user decision. Using a behavioural approach, Wilmot and $\mathrm{Fu}$ [4] propose a model estimating a joint decision, generation with departure time, in the face of an oncoming hurricane, as a series of binary choices over time. Models termed sequential binary logit are proposed, simulating the probability of a household evacuating at each time period prior to a dangerous event. These models are first derived using the random utility principle.

In relation to destination choice simulation, a disaggregate choice model for hurricane evacuation was developed with post-Hurricane Floyd survey data collected in South Carolina in 1999. A multinomial logit model was used to investigate the effect of risk areas in the path, or projected path, of a hurricane, and destination socioeconomic and demographic characteristics on destination choice behaviour. Models were developed for persons evacuating to friends or relatives, or hotels or motels separately [5].

However, since RP data are not available for all dangerous events, models specified for hurricane evacuation, which are derived from observation of past evacuation behaviour, cannot be directly applied to other dangerous events. To solve this problem, in a previous work we proposed a system of models [1, 7] which use RP data obtained during evacuation trials. We simulated the hypothetical scenario of a dangerous event with delayed effect, namely an incident involving a tanker transporting hazardous goods on a workday morning. The RP data obtained during evacuation trials are slightly affected by the laboratory effect, because each user participating in evacuation trials knows that he/she runs no real danger.

Thus, given this hybrid kind of data, termed RP with laboratory effect, we calibrated several sub-models included in the general system of models: generation, distribution and modal choice. The generation sub-model gives the level of demand in the study area according to the reference period and the population category; the modal split sub-model gives the number of people using a given transport mode from a certain origin to a certain refuge area; the distribution submodel gives the number of people choosing a given refuge area. Each sub-model is specified for different user categories using data obtained from real experimentation in the urban area of Melito Porto Salvo (Italy) in relation to the SICURO research project [1, 7-9]. This general system of models is enhanced by applying the dynamic - sequential approach in the simulation [10]. 
Moreover, from the SICURO research project, models simulating path choice for emergency vehicles are proposed by Vitetta et al. [11-13], Polimeni et al. $[14,15]$. Models simulating the interaction of demand and supply by Vitetta et al. [16-18], Marciano et al. [19, 20]; for this theme we recall also Russo and Vitetta [21].

In this work, we introduce hypothetical scenarios to analyze, in the absence of evacuation trials, the statistical behavioural of user in evacuation conditions from their statements. We propose several emergency situations, which could be considered the choice context of stated preference (SP) surveys. SP represents the stated behaviour of users in relation to hypothetical contexts and should be considered as complementary to traditional RP surveys.

SP investigations are a set of techniques that use the statements of respondents about their preferences in hypothetical scenarios or contexts. To construct a stated preference experiment some elements have to be defined: the composition of the choice contexts proposed to the decision maker in terms of alternative options, attributes considered for each alternative, varying levels of attributes, the type of inquiry regarding the decision-maker's preferences and the way in which the interview is conducted. In relation to the type of requested preference, the decision maker faced with a scenario can express different types of preference:

- choice, that is the respondent indicates which option to choose in that context (this is the most reliable method);

- ranking, that is the respondent must order the options according to their degree of preference;

- rating, that is the respondent must give a measure of preference (vote) in a default scale for each alternative option.

Finally, the interviews may be conducted in various ways: the more traditional ones in which the decision maker presents ballot papers with all information relating to a choice context, to more sophisticated techniques in which the interviewer uses a computer and the scenarios are generated in real time taking into account responses from the decision maker.

Below we describe hypothetical scenarios proposed to the sample considered (section 2) and obtained results from statistical analysis of statements (section 3); we then draw our main conclusions (section 4).

\section{Description of hypothetical scenarios}

This section shows hypothetical scenarios proposed during an experiment conducted at the Laboratory for Transport Systems Analysis (LAST), Department of Computer Science, Mathematics, Electronics and Transport (DIMET) of Mediterranea University of Reggio Calabria. The LAST is located on the second floor of the Engineering School building within the university campus.

We interviewed a sample of people belonging to the DIMET. The sample has a high cultural level as it includes final year students at the School of Engineering, graduate students or postdoctoral students, researchers and 
lecturers. We asked everyone to fill out an information sheet on their socioeconomic characteristics, containing the following data:

- age

- marital status (married or single)

- driving license (yes or no)

- car ownership (yes or no)

- professional status (employed or not)

- participation in a previous evacuation trial (yes or no).

The experiment was developed as described below. The analyst read aloud the description of six hypothetical emergency scenarios, one scenario at a time. Each user in the sample then had to fill out a paper ballot with all information relating to a choice context (traditional method), choosing from a range of alternative options, as in the choice method of SP surveys (see section 1).

In general, this analysis must be carried out for two basic reasons: analysis of the market research type, to establish the importance of various factors in the choice (so that these can be taken into account by the transport operator); analysis to forecast future flows of demand by the different modes for planning purposes. These two types of analysis are fundamentally different insofar as for market research analysis the determinants of demand are required per se, whereas, in the case of forecasts for planning purposes, factors influencing modal split are only required as an intermediate stage in the forecasting process. In this work, we focus on the first kind of analysis, and we pursue two main classes of objectives:

- a first-level objective, to evaluate user behaviour, in relation to the decision to evacuate or not, of toward evacuate and by which transport mode (the formal transportation decisions);

- a second-level objective, to evaluate user behaviour in relation to the informer and to the kind of dangerous event.

Emergency scenarios are synthetically described in table 1. Scenarios 1 and 2 are very similar: in both cases the same kind of emergency is proposed, the difference is the informer who communicates the state of emergency to potential stakeholders: while for scenario 1 the informer is a stranger, for scenario 2 , it is the head of department. The objective is to determine whether, according to the reliability of the informer who broke the news, different behaviour may be found in users.

Scenario 3 is more complex: it includes the possibility that a stream running by the Engineering School may flood, and a scheduled evacuation time for those involved. The objective is to test whether, in this case, the user is willing to follow precise directions provided by the system operator (in this case, the mayor of the city), or panic, choosing to leave the area affected by the emergency immediately.

Scenario 4 was constructed by considering an environment different from the LAST, within the university campus: the environment is the city centre, and the objective is to test any differences in behaviour under more critical traffic conditions, in an urban rather than a campus context. Finally, scenarios 5 and 6 are similar to scenarios 1 and 2, but a different choice structure is proposed to 


\section{Table 1: $\quad$ Scenario description.}

\begin{tabular}{|c|c|}
\hline $\begin{array}{c}\text { Scenario } \\
1\end{array}$ & $\begin{array}{c}\text { Thursday, February 24, 2011, 11:07 am. } \\
\text { You are working at the LAST laboratory of the University of Reggio } \\
\text { Calabria on a report to be delivered shortly. Suppose a stranger suddenly } \\
\text { enters your room and asks you to leave your workplace, because a bomb is } \\
\text { going to explode in the laboratory. The stranger tells you to go and reach } \\
\text { Piazza San Brunello. The stranger suggests that, to allow faster flow, he/she } \\
\text { will open the locked gate to the Agricultural College of the University of } \\
\text { Reggio Calabria. }\end{array}$ \\
\hline $\begin{array}{l}\text { Scenario } \\
\quad 2\end{array}$ & $\begin{array}{c}\text { Thursday, March 9, 2011, 10:31 am. } \\
\text { You are working at the LAST laboratory of the University of Reggio } \\
\text { Calabria on a report to be delivered shortly. Suppose your department head } \\
\text { suddenly enters your room and you to leave your workplace, because a } \\
\text { bomb is going to explode in the laboratory. The department head tells you } \\
\text { to go and reach Piazza San Brunello. The head suggests that, to allow faster } \\
\text { flow, he/she will open the locked gate to the Agricultural College of the } \\
\text { University of Reggio Calabria. }\end{array}$ \\
\hline $\begin{array}{l}\text { Scenario } \\
\quad 3\end{array}$ & $\begin{array}{l}\text { Friday, February 25, 2011, at 10:26. } \\
\text { You are working at the LAST laboratory of the University of Reggio } \\
\text { Calabria on a report to be delivered shortly. For some days it has rained } \\
\text { continuously, but at this time of year it is not unusual in Reggio Calabria. } \\
\text { Suddenly you hear about the Annunziata torrent that is about to flood, and } \\
\text { in order to avoid the disastrous effects on the city, the Mayor has prepared } \\
\text { an evacuation plan, indicating evacuation time and place of storage for } \\
\text { different areas. The evacuation time limit for the area is set for 12:30 and } \\
\text { the place of storage to be reached is the Palace of the Regional Council. In } \\
\text { the University the news spreads that the gate will be opened that blocks the } \\
\text { way to the Agricultural College of the University of Reggio Calabria. }\end{array}$ \\
\hline $\begin{array}{c}\text { Scenario } \\
4\end{array}$ & $\begin{array}{l}\text { Thursday, February 17, 2011, 10:07 am. } \\
\text { You are in the town hall, in the Hall of Lamps, for a conference on the } \\
\text { Euro-Mediterranean area. You have arrived at around 9.20, after parking } \\
\text { your car on Via Marina at the Villa Zerbi. Suddenly, a stranger breaks into } \\
\text { the hall and tells you that you must evacuate the building: a tanker full of } \\
\text { flammable liquid is blocked between Via Marina and Corso Garibaldi and } \\
\text { is about to explode. }\end{array}$ \\
\hline $\begin{array}{l}\text { Scenario } \\
5\end{array}$ & $\begin{array}{c}\text { Thursday, February 24, 2011, 11:07 am. } \\
\text { As scenario 1 }\end{array}$ \\
\hline $\begin{array}{l}\text { Scenario } \\
6\end{array}$ & $\begin{array}{c}\text { Thursday, March 9, 2011, 10:31 am. } \\
\text { As scenario } 2\end{array}$ \\
\hline
\end{tabular}

sample users. The goal here is to determine whether the choice of mode and destination is jointly made or otherwise, in emergency conditions, compared to what usually happens in ordinary conditions.

For all scenarios, as well as checking the willingness of the user to evacuate, information on the choice of transport mode (car or foot) and destination (home or safe place indicated) is required.

Scenarios 1-3 and 5-6 are set in the university campus (figure 1); scenario 4 is set downtown (figure 2). 


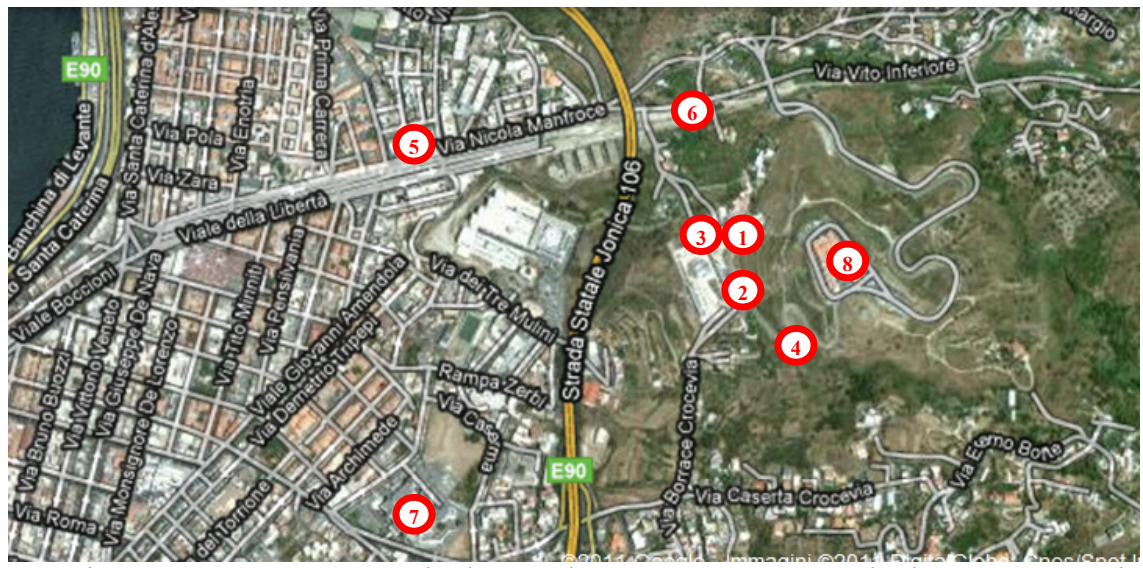

Legend: 1. LAST; 2. Engineering School car park; 3. Main Engineering School exit; 4. Gate to the Agricultural College; 5. Piazza San Brunello; 6. Annunziata torrent; 7. Palace of the Regional Council; 8. Agricultural College.

Figure 1: View of the university campus.

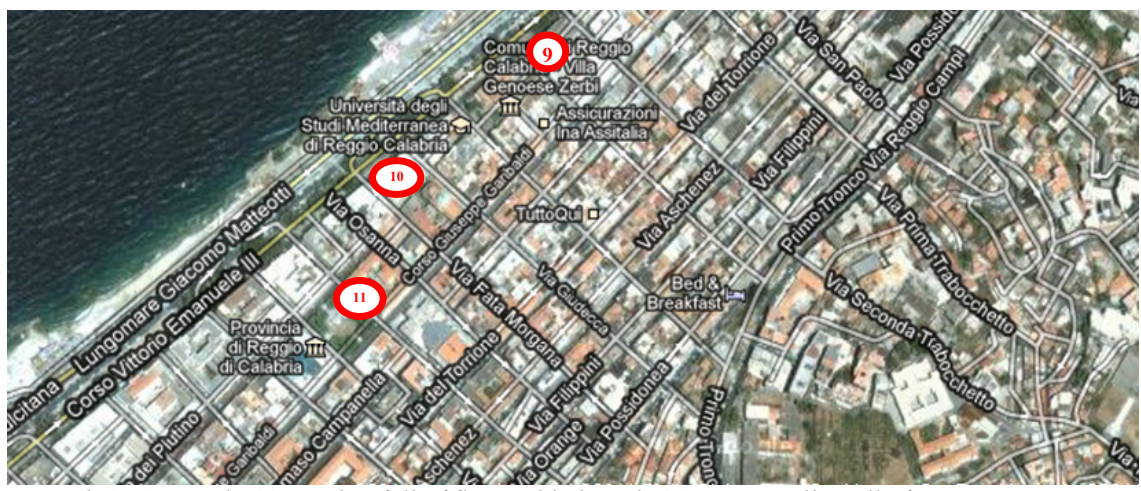

Legend: 9. Car park; 10. Tanker full of flammable liquid; 11. Town Hall, Hall of Lamps.

Figure 2: View of downtown.

\section{Statistical analysis of responses}

The sample included 25 people, 12 women and 13 men, aged between 23 and 54 years. Six of them were married (five men and one woman) and only 8 had participated in previous evacuation trials. In percentage terms, $92 \%$ of the total were licensed drivers and $76 \%$ owned a car, while only $60 \%$ of the sample were employees. 


\subsection{Scenario 1 results}

The scenario 1 results are expressed in percentages compared to the total number of users and show that:

- $88 \%$ of users leave the laboratory, while the remaining $12 \%$ do not trust the received information;

- $32 \%$ decide to move on foot, $56 \%$ choose to go to the campus car park and travel by car;

- the users who decide to move on foot choose to leave by the Engineering gate and then reach the place designated by the stranger;

- of the users who decide to travel by car, $20 \%$ decide to continue to the Agricultural College and $36 \%$ to leave by the Engineering School gate; $32 \%$ then decide to go to the place designated by the stranger and $24 \%$ to reach their homes.

\subsection{Scenario 2 results}

The scenario 2 results are expressed in percentages compared to the total number of users and show that:

- $96 \%$ of users leave the laboratory, while the remaining $4 \%$ do not trust the received information;

- $48 \%$ decide to move on foot, $48 \%$ choose to go to the campus car park and travel by car;

- as regards users who decide to move on foot, $12 \%$ decide to continue to the Agricultural College and 36\% leave by the Engineering School gate; $40 \%$ then decide to go to the place designated by the head of department and $8 \%$ to reach their homes;

- of the users who decide to travel by car, $24 \%$ decide to continue to the Agricultural College and 24\% to leave by the Engineering School gate; $40 \%$ then decide to go to the place designated by the head of department and $8 \%$ to reach their homes.

\subsection{Scenario 1 vs. Scenario 2}

A comparison between the results obtained from scenarios 1 and 2 shows that:

- for scenario 2, the percentage of users who decide to leave the workplace increases by 8 percentage points: people perceive the information on emergency conditions from the director of the department as being more reliable;

- the percentage of users who choose to go out on foot, in comparison with scenario 1 , increases, and then users who leave in scenario 2, considering the received information more reliable, decide to get out on foot;

- the number of users who choose to go out via the Agricultural College increases by 15 percentage points, as people consider the received information more reliable; 
- as regards total users, for scenario 2, the number of users who decide to reach the place designated by the informer increased by 10 percentage points.

\subsection{Scenario 3 results}

In comparison with scenarios 1 and 2, the dangerous event changes in scenario 3: even if both events have delayed effects in time, in scenarios 1 and 2 the kind of event is anthropogenic and related to the workplace of users; in scenario 3 the disaster is natural and concerns a wider area.

Scenario 3 results are expressed in percentages compared to the total number of users and show that:

- $52 \%$ of users leave the laboratory immediately and do not wait for the specified time of evacuation;

of those who leave immediately ( $52 \%$ of the total)

- $24 \%$ decide to move on foot, while the remaining $28 \%$ choose to go to the campus car park and travel by car;

- $40 \%$ decide to leave by the Engineering School gate, while the remaining $12 \%$ decide to continue to the Agricultural College (these are included in the set of users which choose the car as transport mode);

- $36 \%$ of the total decide to get to the place designated by the mayor, while the remaining $16 \%$ reach their homes;

of those who wait for the specified time of evacuation ( $48 \%$ of the total)

- $44 \%$ of users leave the laboratory while $4 \%$ stay behind;

- $20 \%$ decide to move on foot, while the remaining $24 \%$ choose to go to the campus car park and travel by car;

- $16 \%$ decides to leave by the Engineering School gate, while the remaining 28\% decide to continue to the Agricultural College (the latter are in the set of users who choose the car as a transport mode);

- $36 \%$ of the total decide to get to the place designated by the mayor, while the remaining $8 \%$ go home.

\subsection{Scenario 3 vs. Scenario 1 and 2}

A comparison of the results obtained for scenarios 1, 2 and 3 shows that, in relation to first-level objectives, the evacuation percentage in scenario 2 is higher than in scenarios 1 and 3 . This could be due to the informer (second-level objectives), as the information received is perceived as less reliable if the informer is not the head of department (scenario 2) but a stranger (scenario 1) or even the mayor (scenario 3). Indeed, in scenario 2 as many as $96 \%$ of the total follow advice given by the informer, namely the head of department; in scenario $1,88 \%$ of the total follow indications made by the informer, namely a stranger; in scenario 3 only $48 \%$ of the total follow indications laid down by the informer, namely the mayor, although the hypothesis of a different event might give rise to some bias.

The trend is the same if we consider other choice levels (first-level objectives). If we analyze, for example, choice of final destination, in scenario 2 
as many as $80 \%$ of the total reaches the location indicated by the informer; in scenario 1 this number becomes $64 \%(-16 \%)$; in scenario 3 the figure drops to $36 \%$ (if we consider only the percentage of the sample who wait for the given evacuation time). Moreover, if we consider the decision to leave by the Engineering School gate or continue to the Agricultural College, recommended by the informer, in scenario 2, the informer's advice is followed by $36 \%$ of the sample; this percentage becomes, respectively, $20 \%$ and $28 \%$ (if we consider only the percentage of the sample which waits for the given evacuation time) in scenarios 1 and 3 . In this last choice, the mayor is considered more reliable than the stranger. Finally, if we consider the kind of event (second-level objectives) it may be noted that the anthropogenic event, occurring in the user's workplace, is perceived as more risky than a natural dangerous event related to a wide area, even if this could also produce dangerous effects on users. Indeed, evacuation percentages are higher in scenarios 1 and 2 than in scenario 3.

\subsection{Scenario 4 results}

The results of scenario 4 are expressed in percentage terms compared to the total number of users. They show that:

- $84 \%$ of users leave immediately while the remaining $16 \%$ wait in the hall to obtain more reliable information;

- $76 \%$ of users move quickly to walk away from the truck, while the remaining $8 \%$ reach their cars to drive away.

\subsection{Scenario 4 vs. Scenario 1}

In this section we compare the results obtained from scenarios 4 and 1, both with an informer who is a stranger. A comparison between the evacuation percentages obtained shows that the information received is perceived as slightly more reliable if the user is in his/her workplace rather than in a new environment (second-level objectives). Indeed, $88 \%$ of users leave the laboratory in scenario 1 , while $84 \%$ of users leave the hall in scenario 4 . Moreover, we note that in scenario $1,64 \%$ of the total decide to get to the place designated by the stranger, while $76 \%$ of users in scenario 4 move quickly to walk away from the truck (first-level objectives). Finally, if we consider the kind of event (second-level objectives), in both scenarios, an anthropogenic event is hypothesised, but with a different localization. In scenario 1, the affected area is the user's workspace, in scenario 4 it is downtown. In this case evacuation percentages are similar and slightly higher for scenario 1 .

\subsection{Scenario 5 results}

The results of scenario 4 are expressed in percentages compared to the total number of users and show that:

- $84 \%$ of users leave the laboratory, while the remaining $16 \%$ do not trust the received information;

- $40 \%$ decide to move on foot by the Engineering School gate; 
- $0 \%$ decide to move on foot, continuing to the Agricultural College;

- $24 \%$ decide to go to the campus car park and travel by car, by the Engineering School gate;

- $20 \%$ decide to go to the campus car park and travel by car, continuing to the Agricultural College;

- $60 \%$ of the total decide to get to the place designated by the stranger, while the remaining $24 \%$ go home.

\subsection{Scenario 5 vs. Scenario 1}

In this section we compare the results obtained from scenario 5 and 1 , both with an informer who is a stranger but with a different choice structure of the alternatives proposed to the sample; the choice alternatives are related to a joint choice of destination and mode, in scenario 5 , and to the single choice first of destination, and then of mode in scenariol.

A comparison between evacuation percentages obtained shows that from scenario 1 to scenario 5 the number of users leaving the laboratory decreases by 4\%. If we consider first-level objectives:

- in relation to the decision to get to the place designated by the stranger, the same percentages are obtained ( $60 \%$ of total users);

- also in relation to the decision to go through the Agricultural College, the same percentage are obtained (20\% of total users);

- in relation to the decision to move on foot or by car and to continue to the Agricultural College or leave by the Engineering School gate, the different choice structures proposed to the sample show the following differences among user responses:

- from the choice structure proposed in scenario 1 , we obtain that $32 \%$ of users choose first to move on foot and then to continue by the Engineering School gate, while in scenario 5 this joint percentage is $40 \%$;

$\circ \quad$ in scenario 1 , none of the users choose first to move on foot and then to continue to the Agricultural College, as in scenario 5;

$0 \quad$ in scenario $1,36 \%$ of users choose first to move by car and then to continue by the Engineering School gate, while in scenario 5 this joint percentage is $24 \%$;

$0 \quad$ in scenario 1 , the same number of users $(20 \%)$ choose first to move by car and then to continue to the Agricultural College as those in scenario 5 who choose mode and destination jointly.

In relation to the second-level objectives, the information received is perceived as more reliable in scenario 1 , even if slight variations are obtained between user percentages.

\subsection{Scenario 6 results}

The scenario 6 results are expressed in percentages compared to the total number of users and show that: 
- $96 \%$ of users leave the laboratory, while the remaining $4 \%$ do not trust the received information;

- $28 \%$ decide to move on foot via the Engineering School gate;

- $16 \%$ decide to move on foot, continuing to the Agricultural College;

- $28 \%$ decide to go to the campus car park and travel by car, by the Engineering School gate;

- $24 \%$ decide to go to the campus car park and travel by car, continuing to the Agricultural College;

- $84 \%$ of total users decide to get to the place designated by the stranger, while the remaining $12 \%$ to go home.

\subsection{Scenario 6 vs. Scenario 2 and 5}

In this section we compare the results obtained from:

- scenarios 6 vs. 2 , both with an informer who is the head of department, but with a different structure of the choice alternatives proposed to the sample; the choice alternatives are related to a joint choice of destination and mode, in scenario 6 , and to the single choice, first of destination, and then of mode, in scenario 2 (first-level objectives);

- scenarios 6 vs. 5, both with the same structure of the choice alternatives proposed to the sample, but a different informer, who is a stranger in scenario 5 and the head of department in scenario 6 (second-level objectives).

In relation to scenarios 6 and 2, a comparison between the evacuation percentages obtained shows that the same percentage of users leave the laboratory (96\%). If we consider the other choice level:

- in relation to the decision to get to the place designated by the director, in scenario 6 this number increases by 20 percentage points;

- in relation to the decision to go on to the Agricultural College, for this choice in scenario 6 this share of users increases by $4 \%$;

- in relation to the decision to move on foot or by car and to continue to the Agricultural College or by the Engineering School gate, the different structures of choice proposed to the sample show several differences in user responses, namely:

0 from the choice structure proposed in scenario 2, we obtain that $36 \%$ of users who choose first to move on foot and then to continue by the Engineering School gate, while in scenario 6 this joint percentage is $28 \%$;

$0 \quad$ in scenario $2,12 \%$ of users choose first to move on foot and then to continue to the Agricultural College, while in scenario 6 this combined figure is $16 \%$;

$0 \quad$ in scenario 2, the number of users who choose first to move by car and then to continue by the Engineering School gate amounts to $24 \%$, while in scenario 6 this joint percentage is $28 \%$;

$0 \quad$ in scenario 2, the percentage of users who choose first to move by car and then to continue to the Agricultural College is to the same 
as the percentage of users who, in scenario 6 , choose mode and destination jointly.

In relation to scenarios 6 and 5, comparison between the evacuation percentages obtained shows that the percentage of users that leave the laboratory in scenario 6 increases by $12 \%$ to $96 \%$. Moreover:

- the number of users who go to the place designated by the informer, in scenario 6 , increases by $24 \%$;

- the number of users who choose jointly to move on foot and to continue by the Engineering School gate in scenario 6 decreases by $12 \%$;

- the number of users who choose jointly to move on foot and to continue to the Agricultural College in scenario 6 increases by $16 \%$. Then the informer is perceived as more reliable;

- the number of users who choose jointly to go out by car and to continue by the Engineering School gate is $24 \%$ in scenario 5, while in scenario 6 it is $28 \%$;

- the number of users who choose jointly to leave by car and continue to the Agricultural College is $20 \%$ in scenario 5, while in scenario 6 this joint percentage is $24 \%$.

\section{Conclusion}

In this work several hypothetical scenarios were proposed, considering three kinds of dangerous events, with delayed effects in time, in order to analyze user behaviour in emergency conditions. Our sample comprised 25 users with a high cultural level belonging to the DIMET.

The results point out the importance of the informer: user behaviour in evacuation conditions changes whether the informer is the head of department, who is considered more reliable, a stranger or even the mayor, who emerge as less reliable. This trend is the same if we also consider other user decisions, that is the final destination (the place designated by the stranger or home) and the possibility of continuing to the Agricultural College, a choice advised by the informer, rather than leaving by the Engineering School gate. Panic is a significant factor, as in scenario 3 less than $50 \%$ of the total number of users in the sample follow the mayor's instructions and wait for the given evacuation time. Finally, in scenario 4, the different conditions of users, who are not in our workplace, suggest behaviour which is somewhat unpredictable and controlled.

Our future objectives are to expand the sample in order to calibrate a demand model in evacuation conditions, considering SP data as in the hypothetical scenarios supposed and analyzed in this work. While this work is experimental in respect of second-level objectives, it indicates a trend that requires investigation with a larger sample of users. 


\section{References}

[1] Russo, F., Chilà, G., Safety of users in road evacuation: demand models, Urban Transport XIII, Brebbia C.A. (ed.), WIT Press, 773-782, and in Urban Transport: Safety of Users in Road Evacuation, Russo F. (ed.), WIT Press, 11-20, 2007.

[2] Russo, F., Vitetta, A., Risk evaluation in a transportation system. International Journal of Sustainable Development and Planning, 1 (2), pp. 170-191, 2006.

[3] Wilmot C.G. \& Fu H., Static vs. Dynamic and Aggregate vs. Disaggregate: A Comparison Between Practice and Research in Hurricane Evacuation Travel Demand Modeling. Transp. Res. Board 86th Annual Meeting, 2007.

[4] Wilmot C.G. \& Fu H., A sequential logit dynamic travel demand model for hurricane evacuation. Transp. Research Record, 1882, pp.19-26, 2004.

[5] Wilmot, C.G., H. Fu, \&H. Zhang. Modeling the Hurricane Evacuation Response Curve. Transportation Research Record: Journal of Transportation Research Record Board, 2022, pp 94-102, 2007.

[6] Cheng, G., C.G. Wilmot, and R.J. Baker. A destination choice model for hurricane evacuation. In Transp. Research Board Annual Meeting 2008. CD-ROM. Transportation Research Board of the National Academies, Washington, D.C., 2008.

[7] Russo, F., Chilà, G., Safety of users in road evacuation: RP vs. SP surveys in demand analysis. In Urban Transport XIV, Brebbia C.A. (ed.), WIT Press, 703-713, 2008

[8] Russo, F., Rindone, C., Safety of users in road evacuation: planning internal processes and guidelines. WIT Transactions on the Built Environment Volume 96, pp. 825-834., 2007.

[9] Russo F. \& Rindone C., Safety of users in road evacuation: the logical framework approach in evacuation planning. Proc. of Urban Transport $X I V$, Urban Transport and the Environment in the 21st century, Brebbia C.A. (ed.), WIT Press, Southampton, pp. 751-760, 2008.

[10] Russo F. \& Chilà G., A sequential dynamic choice model to simulate demand in evacuation conditions. Proc. of Risk Analysis VII \& Brownfields $V$, Brebbia C.A. (ed.), WIT Press, Southampton, pp. 431-442, 2010.

[11] Vitetta, A., Quattrone, A., Polimeni, A., Safety of users in road evacuation: design of path choice models for emergency vehicles. WIT Transactions on the Built Environment Volume 96, pp. 803-812, 2007.

[12] Vitetta A., Quattrone A. \& Polimeni A., Safety of users in road evacuation: algorithms for path design of emergency vehicles, Proc. of Urban Transport XIV, Urban Transport and the Environment in the 21st century, Brebbia C.A. (ed.), WIT Press, Southampton, pp. 727-737, 2008.

[13] Vitetta A., Quattrone A. \& Polimeni A., Safety of users in road evacuation: Modelling and DSS for paths design of emergency vehicles. Proc. of Sustainable Development and Planning IV, vol.1, Brebbia C.A. (ed.), WIT Press, Southampton, pp. 485-495, 2009. 
[14] Polimeni A., Quattrone A. \& Vitetta A., A tool for tracing emergency vehicles during evacuation. Proc. of Urban Transport XVI, Urban Transport and the Environment in the 21st century, Brebbia C.A. (ed.), WIT Press, Southampton, pp. 325-333, 2010.

[15] Polimeni A., Quattrone A. \& Vitetta A., An approach to designing vehicle routes in evacuation conditions. Proc. of Risk analysis VII \& Brownfields V, Brebbia C.A. (ed.), WIT Press, Southampton, pp.469-480, 2010.

[16] Vitetta A., Musolino G. \& Marcianò F.A., Safety of users in road evacuation: Supply and demand-supply interaction models for users. Proc. of Urban Transport XIII, Urban Transport and the Environment in the 21st century, Brebbia C. A. (ed.), WIT Press, Southampton, pp. 783-792, 2007.

[17] Vitetta A., Musolino G. \& Marcianò F.A., Safety of users in road evacuation: calibration of cost functions and simulation. Proc. of Urban Transport XIV, Urban Transport and the Environment in the 21st century, Brebbia C.A. (ed.), WIT Press, Southampton, pp. 715-725, 2008.

[18] Vitetta A., Musolino G. \& Marcianò F.A., Safety of users in road evacuation: Modelling and DSS for transport supply and supply-demand interaction. Proc. of Sustainable Development and Planning IV, vol.1, Brebbia C.A. (ed.), WIT Press, Southampton, pp. 475-484, 2009.

[19] Marcianò F.A., Musolino G. \& Vitetta A., A system of models for signal setting design of a signalized road network in evacuation conditions. Proc. of Urban Transport XVI, Urban Transport and the Environment in the 21st century, Brebbia C.A. (ed.), WIT Press, Southampton, pp.313-323, 2010.

[20] Marcianò F.A. , Musolino G. \& Vitetta A., Signal setting design on a road network: application of a system of models in evacuation conditions. Proc. of Risk Analysis VII \& Brownfields V, Brebbia C.A. (ed.), WIT Press, Southampton, pp.443-454, 2010.

[21] Russo F. \& Vitetta A., Reverse assignment: calibrating link cost functions and updating demand from traffic counts and time measurements. Inverse Problems in Science \& Engineering, ISSN 1741-5977 print/ISSN17415985 Taylor \& Francis DOI: 10.1080/17415977.2011.565339. Forthcoming. 